\title{
Academic Stress among Nursing Students in a Private University at Puerto Rico, and Its Association with Their Academic Performance
}

\author{
Josue Pacheco-Castillo1, Maria-Jesus Casuso-Holgado², Maria-Teresa Labajos-Manzanares², \\ Noelia Moreno-Morales ${ }^{2}$
}

${ }^{1}$ School of Sciences Health, Nursing Department, Ana G. Mendez University, Gurabo, Puerto Rico

${ }^{2}$ Faculty of Health Sciences, Doctoral Program in Health Sciences, Malaga University, Malaga, Spain

Email: eusoj1212@yahoo.com

How to cite this paper: Pacheco-Castillo, J., Casuso-Holgado, M.-J., Labajos-Manzanares, M.-T. and Moreno-Morales, N. (2021) Academic Stress among Nursing Students in a Private University at Puerto Rico, and Its Association with Their Academic Performance. Open Journal of Nursing, 11, 742-756.

https://doi.org/10.4236/ojn.2021.119063

Received: February 20, 2020

Accepted: September 15, 2021

Published: September 18, 2021

Copyright $\odot 2021$ by author(s) and Scientific Research Publishing Inc. This work is licensed under the Creative Commons Attribution International License (CC BY 4.0).

http://creativecommons.org/licenses/by/4.0/

\section{(c) (i) Open Access}

\begin{abstract}
Background: Nursing programs have distinguished themselves for being rigorous. The college experience emerges with new challenges and demands that require adaptation in order to cope with academic stress. Situation that could lead to a non adaptive institutional environment. Objective: The purpose of this research was to determine and analyze possible repercussions of academic stress in nursing students in a Puerto Rican private university and how it affects academic performance in students. Materials and Methods: The selected methodology is a cross-sectional study. The simple random sample was comprised of 168 nursing students who were enrolled in associate degree (29.2\%) and bachelor's degree programs in nursing (70.8\%). Data was collected through standardized Academic Stress (CEA, by its acronym in Spanish). Results: The study shows that academic stressors are correlated with the grade point average. In addition, correlation between academic stress and the performance rate was found, especially in terms of the difficulty to approve enrolled credits. Conclusions: Nursing students suffer from stress regardless their academic degree. Academic stress affects academic performance of students despite their use of management strategies.
\end{abstract}

\section{Keywords}

Academic Stress, Academic Performance, Stress Responses, Coping Strategies, Nursing Students

\section{Introduction}

In recent years, there has been a growing interest in researching the implications 
of stress and its prevalence in the academic field. Therefore, it has become necessary to specifically conduct research related to stressful situations in students within the health science community, particularly in the fields of medicine and nursing [1]-[6]. This student community is one with the highest stress levels surpassing the general student population and students belonging to other fields of knowledge [7] [8]. Furthermore, students admitted in careers related to the health sciences need to respond adequately to rigorous curricula and difficult emotional experiences. These situations demand the nursing student, a high degree of tolerance to frustration, and a high sense of compromise, to overcome difficulties presented during the adaptation process at the university level, which may affect their learning capacity and academic achievement goals [9].

Nursing students in Puerto Rico are not exempt from suffering academic stress. The nursing profession in the island of Puerto Rico faces constant challenges that stem, in part from state (Puerto Rico) and national (United States) requirements which regulate the nursing profession, a situation which entails significant curricular changes. The learning environment is a challenge that demands many hours of study and clinical practice since it is to be assessed by the United States national standards. Therefore, the required teaching standards are rigorous, plus the academic level of competitiveness required of the students is high. It is for this reason that nursing students in Puerto Rico become an academic stress risk prone population. Due to this fact, it is necessary to conduct research on this phenomenon.

According to the data obtained from the Consejo de Educacion Superior de Puerto Rico [10], less than $40 \%$ of the students obtain their degree, and over $50 \%$ drop out of college within the first year. As a preventive measure, in its assistance services, the Puerto Rican private university where the study was conducted, and from which the nursing students' sample was selected, includes a first-year supervision from the Dean of Student Affairs to help students cope within their first year of studies. The Nursing program that belongs to the university, reports a retention rate of $67 \%$ [11]. Nonetheless, the graduation rate reports a low percentage, under $27 \%$, which supposes that a clear majority of students endure diverse personal and other types of situations that refrain them from completing their academic goals. This might be due to nursing student difficulties on managing academic stress [12] [13] [14] [15] [16], a reason by which it is necessary to conduct rigorous research on academic stress.

The purpose for conducting this research was to determine and analyze possible repercussions of academic stress in nursing students in a Puerto Rican private university and how it affects academic performance in students. Early detection of academic stress in nursing students is a priority endeavor, given the possibility to successfully confront it by using strategies that lessen or eradicate this factor. Therefore, the results of this study, besides filling a scientific and theoretical gap about managing academic stress, will create a foundation upon which academic stress managing techniques can be taught and learned effective- 
ly. Consequently, negative stress management behavior can be successfully confronted. In this way, a more holistic, integral approach to the formation of the whole person can be encouraged, and a contribution to the educational community and to the promotion of mental health can be made.

\section{Method}

\subsection{Population and Sample}

The population of the study was composed of nursing students enrolled to achieve an associate or baccalaureate degrees, and completing either their first, second, third or fourth year of studies, at a private university located in the Center-East zone of Puerto Rico. The students under study belonged to the School of Health Sciences of the mentioned institution. The sample was selected from this student population. A simple random sampling was used, from a population of 610 students at the university campus [11]. The sample, calculated by the Java operation system with a margin of error of $5 \%$ and a prevalence of $17 \%$, resulted in a total sample of 170 individuals with a replacement rate of $50 \%$. The following four inclusion criteria were established: 1) To be enrolled in the nursing program, 2) To be a full time or part time student in the nursing program, 3) To participate voluntarily in the study, and 4) to submit a written consent to gain access to their personal academic record.

\subsection{Instrument}

The instrument used to measure the variable academic stress was the questionnaire: Cuestionario de Estrés Académico (Academic Stress QuestionnaireCEA), originally developed by Cabanach, Valle, Rodríguez \& Piñeiro [17]. The questionnaire was validated in a student population in Spain and contains three subscales: academic stressors subscale (E-CEA); stress response subscale (R-CEA); and coping strategies subscale (A-CEA). Responses to each item are registered in a five-point scale that ranges from: "Never" (1), to "Always" (5).

\subsubsection{Subscale's Descriptions}

A description of each CEA subscale is presented below:

Academic stressors subscale ( $E-C E A)$-Consists of 53 items that measure different situations and/or circumstances that belong to the academic context that, in some measure, can generate pressure in the student in a way that he or she perceives it as a danger or as a threat to his or her wellbeing.

Stress response subscale ( $R$-CEA)-Consists of 22 items that pretend to measure symptoms related to physical, behavioral, and cognitive factors linked to academic stress.

Coping strategies subscale ( $A-C E A)$-Consists of 23 items that pretend to measure behavioral and cognitive ways of coping with academic stress.

\subsubsection{Instrument Translation, Transcultural Adaptation, and Validation}

The Academic Stress Questionnaire (CEA) was modified and adapted to ensure 
it complies with reliability and validity criteria needed to assess academic stress in Puerto Rican nursing students. A $\alpha$ global of 0.80 and coefficients that fluctuate between 0.750 and 0.860 in the subscales were obtained. These coefficients were similar to the Alpha coefficients obtained in Cabanach study [17]. The Puerto Rican modified questionnaire also showed compliance with the reliability and validity requirements to be used in the assessment of academic stress in nursing students in Puerto Rico.

The academic performance of participating nursing students was measured in relation to their academic grade point average, and the number of enrolled and approved credits used to calculate the rate of return; for each participant in the study, using the equation: [(Credits Approved/Credits Enrolled $) \times 100]$. For this sample, the rate of return average score was 83.89 , which, by being near to the maximum score of 100 , indicates a good rate of return. It indicates a high efficiency degree of the student and his or her academic activity within the institution.

\subsection{Procedures}

This research was approved and endorsed by the Board of Institutional Review (IRB), at the Ana G. Mendez University System (SUAGM). The researcher applied and obtained written permission from the Vice-chancellor and the Nursing Program Coordinator where the study took place. A teaching nursing program faculty meeting was arranged to present the intended study and its purpose. Subsequently, the researcher visited each classroom to administer the questionnaire to the selected sample. Each completed questionnaire was put in an unidentified envelope and sealed by the participant, who proceeded him-/herself to place it inside an urn before exiting the classroom.

\subsection{Statistical Analysis}

The SPSS ${ }^{\circledast} 20$ program was used to analyze the data input. An exploratory factorial analysis was performed, along with a reliability analysis to verify the validity of the instrument in terms of its adapted version to Puerto Rican nursing students taking part in the study. A descriptive analysis was also performed, using the averages from central tendency and dispersion measures, as well as frequencies and percentages. To correlate the variables involved, the Pearson correlation coefficient was used, considering a significance value of $p<0.05$. A multivariate analysis (linear regression) was also performed.

\section{Results}

\subsection{Participant Description}

From the 170 participants, only two questionnaires were excluded from the study database, since those two questionnaires left one of the subscales totally unanswered. The study sample was composed of 126 females (75\%), and 42 males (25\%). Regarding academic experience, $70.8 \%$ were nursing baccalaureate 
degree program candidates, and $29.2 \%$ were associate degree nursing program candidates. More than $80 \%$ of the nursing students that participated in the study were full time workers $(86.3 \%)$ and were enrolled in 12 or more credits per semester (89.9\%). Practically, all the students in the study sample (97\%), stated that the nursing profession met their expectations. Further sample descriptions are shown in Table 1.

\subsection{Relation between Academic Stress Perception and Academic Performance}

As part of the analysis, correlation matrices based on Pearson coefficients for CEA subscales and the variables of academic performance were computed and analyzed. Table 2 points to an inverse and statistically significant relationship between the perception of academic stress when considering E-CEA stressors and the academic performance on the nursing students' sample. The answers by item were coded with values according to the Likert scale: "Never" (1), "Sometimes" (2), "Quite often" (3), "Many times" (4), and "Always" (5). The values were summed to obtain a global score for each subscale of the CEA (E-CEA, R-CEA \& A-CEA) and dimensions examined. The global score was divided by the number of items in the corresponding subscale or dimension to obtain mean scores. Global and mean scores were used to perform statistical analyses.

The nine academic stressor dimensions were significantly correlated with the grade point average $(p<0.001)$ and the return rate $(p<0.01)$. The dimension Exams registered a higher Pearson correlation coefficient with both performance variables: grade point average $(r=-0.499)$ and return rate $(r=-0.446)$. Furthermore, the lesser significant coefficients, that constitute a weak correlation between the variables under study, were found between the dimension Faculty methodological deficiencies with the grade point average $(r=-0.274)$ and between the dimension Lack of content values with a rate of retur $n(r=-0.201)$.

The Pearson correlation coefficients matrix between the global scores of the CEA subscales and the variables of academic performance (see Table 3), revealed that the Academic Stressors subscale (E-CEA) and the Stress Response subscale (R-CEA) correlated inverse and significantly with both performance variables $(p<0.05)$. This suggests that the more the perception of academic stressors and responses to stress with adverse symptoms contrary to physical, behavioral, and cognitive student wellbeing, the less will the student academic performance be.

For its part, the Coping Strategies subscale (A-CEA) showed statistically significant, if somewhat weak and positive, correlation with the return rate ( $r=$ $0.191)$. Significant correlations were noted $(p<0.05)$ between the return rate and the three dimensions within the A-CEA: Search for support $(r=0.194)$, Planning $(r=0.182)$ and Positive reassessment $(r=0.172)$. Among the results, the dimension Search for support, stands out with the highest, if somewhat weak, coefficient. 
Table 1. Participant description.

\begin{tabular}{|c|c|c|}
\hline Variables & $f$ & $\%$ \\
\hline \multicolumn{3}{|c|}{ Socio-demographic data } \\
\hline \multicolumn{3}{|l|}{ Gender } \\
\hline Female & 126 & 75.0 \\
\hline Male & 42 & 25.0 \\
\hline \multicolumn{3}{|l|}{ Age } \\
\hline Less than 21 years & 85 & 50.6 \\
\hline 21 years or more & 83 & 49.4 \\
\hline \multicolumn{3}{|l|}{ Marital status } \\
\hline Never married & 133 & 79.2 \\
\hline Married & 18 & 10.7 \\
\hline Consensual relationship, not married & 17 & 10.1 \\
\hline \multicolumn{3}{|l|}{ With whom lives while studying } \\
\hline Lives with family & 133 & 79.2 \\
\hline Does not live with family & 35 & 20.8 \\
\hline \multicolumn{3}{|l|}{ Employment status } \\
\hline Employed & 86 & 51.2 \\
\hline Not employed & 82 & 48.8 \\
\hline \multicolumn{3}{|c|}{ Academic Background } \\
\hline \multicolumn{3}{|l|}{ Study Program } \\
\hline Bachelor degree in Nursing & 119 & 70.8 \\
\hline Associate degree in Nursing & 49 & 29.2 \\
\hline \multicolumn{3}{|l|}{ Years of study } \\
\hline First year & 43 & 25.6 \\
\hline Second year & 45 & 26.8 \\
\hline Third year & 41 & 24.4 \\
\hline Fourth year & 39 & 23.2 \\
\hline \multicolumn{3}{|l|}{ Academic load } \\
\hline Full time & 145 & 86.3 \\
\hline Part time & 23 & 13.7 \\
\hline \multicolumn{3}{|c|}{ Number of credits enrolled regularly per semester ${ }^{1}$} \\
\hline 12 credits or more & 151 & 89.9 \\
\hline Less than 12 credits & 17 & 10.1 \\
\hline \multicolumn{3}{|l|}{ Nursing profession meets expectations } \\
\hline Totally-A lot & 150 & 89.3 \\
\hline Partly-Few & 18 & 10.7 \\
\hline
\end{tabular}

${ }^{1}$ On average, the total number of credits enrolled by students was 77 credits and the passing of these was 66 credits. The mean score of the student academic grade average was 2.73 . 
Table 2. Pearson correlation coefficients between E-CEA dimensions and academic performance on the nursing students sample.

\begin{tabular}{|c|c|c|c|c|c|c|c|c|c|c|c|}
\hline & & TR & Method ef. & $\begin{array}{l}\text { Over } \\
\text { load }\end{array}$ & $\begin{array}{l}\text { Publ } \\
\text { intv }\end{array}$ & $\begin{array}{l}\text { Poor } \\
\text { relat }\end{array}$ & $\begin{array}{l}\text { Lack } \\
\text { contr }\end{array}$ & $\begin{array}{c}\text { Lack } \\
\text { Cont val. }\end{array}$ & $\begin{array}{c}\text { Low acad } \\
\text { s.e. }\end{array}$ & Exam & $\begin{array}{c}\text { Impo } \\
\text { part }\end{array}$ \\
\hline \multirow{2}{*}{ Grade point average (GPA) } & $r$ & $0.665^{\star *}$ & $-0.274^{* *}$ & $-0.376^{* *}$ & $-0.373^{\star *}$ & $-0.393^{\star *}$ & $-0.376^{* *}$ & $-0.280^{* *}$ & $-0.306^{\star *}$ & $-0.499^{* *}$ & $-0.291^{\star *}$ \\
\hline & $p$ & 0.000 & 0.000 & 0.000 & 0.000 & 0.000 & 0.000 & 0.000 & 0.000 & 0.000 & 0.000 \\
\hline \multirow{2}{*}{ Rate of return (RR) } & $r$ & 1 & $-0.238^{* *}$ & $-0.313^{\star *}$ & $-0.255^{\star *}$ & $-0.387^{\star \star}$ & $-0.353^{\star \star}$ & $-0.201^{\star *}$ & $-0.286^{\star *}$ & $-0.446^{\star *}$ & $-0.271^{\star \star}$ \\
\hline & $p$ & & 0.002 & 0.000 & 0.001 & 0.000 & 0.000 & 0.009 & 0.000 & 0.000 & 0.000 \\
\hline \multirow{2}{*}{$\begin{array}{l}\text { Faculty methodological } \\
\text { deficiencies }\end{array}$} & $r$ & & 1 & $0.626^{\star *}$ & $0.452^{* *}$ & $0.597^{\star *}$ & $0.580^{\star *}$ & $0.575^{\star *}$ & $0.550^{\star *}$ & $0.493^{\star *}$ & $0.569^{* *}$ \\
\hline & $p$ & & & 0.000 & 0.000 & 0.000 & 0.000 & 0.000 & 0.000 & 0.000 & 0.000 \\
\hline \multirow{2}{*}{ Student overload } & $r$ & & & 1 & $0.376^{* *}$ & $0.681^{* *}$ & $0.761^{* *}$ & $0.534^{* *}$ & $0.787^{* *}$ & $0.530^{* *}$ & $0.673^{* *}$ \\
\hline & $p$ & & & & 0.000 & 0.000 & 0.000 & 0.000 & 0.000 & 0.000 & 0.000 \\
\hline \multirow{2}{*}{ Public Interventions } & $r$ & & & & 1 & $0.342^{* *}$ & $0.386^{* *}$ & $0.259^{* *}$ & $0.386^{* *}$ & $0.499^{* *}$ & $0.313^{* *}$ \\
\hline & $p$ & & & & & 0.000 & 0.000 & 0.001 & 0.000 & 0.000 & 0.000 \\
\hline \multirow{2}{*}{$\begin{array}{l}\text { Poor social relations within } \\
\text { the academic context }\end{array}$} & $r$ & & & & & 1 & $0.699 * *$ & $0.505^{\star *}$ & $0.763^{* *}$ & $0.530^{* *}$ & $0.815^{\star *}$ \\
\hline & $p$ & & & & & & 0.000 & 0.000 & 0.000 & 0.000 & 0.000 \\
\hline \multirow{2}{*}{$\begin{array}{l}\text { Lack of control over own } \\
\text { academic performance }\end{array}$} & $r$ & & & & & & 1 & $0.659^{* *}$ & $0.855^{* *}$ & $0.416^{* *}$ & $0.695^{\star *}$ \\
\hline & $p$ & & & & & & & 0.000 & 0.000 & 0.000 & 0.000 \\
\hline \multirow{2}{*}{ Lack of content values } & $r$ & & & & & & & 1 & $0.613^{* *}$ & $0.241^{* *}$ & $0.485^{\star *}$ \\
\hline & $p$ & & & & & & & & 0.000 & 0.002 & 0.000 \\
\hline \multirow[b]{2}{*}{ Low academic self-esteem } & $r$ & & & & & & & & 1 & $0.430^{* *}$ & $0.789^{* *}$ \\
\hline & $p$ & & & & & & & & & 0.000 & 0.000 \\
\hline \multirow{2}{*}{ Exams } & $r$ & & & & & & & & & 1 & $0.421^{* *}$ \\
\hline & $p$ & & & & & & & & & & 0.000 \\
\hline
\end{tabular}

${ }^{* *}$ Correlation is significant at the 0.01 level (2-tailed).

Table 3. Pearson correlation coefficients between global scores of the CEA subscales and the academic performance variables on the nursing students sample.

\begin{tabular}{|c|c|c|c|c|c|c|}
\hline Variables & & GPA & $\mathrm{RR}$ & E-CEA & R-CEA & A-CEA \\
\hline \multirow{2}{*}{ Grade Point Average (GPA) } & $r$ & 1 & $0.665^{* *}$ & $-0.443^{* *}$ & $-0.241^{\star *}$ & 0.093 \\
\hline & $p$ & & 0.000 & 0.000 & 0.002 & 0.232 \\
\hline \multirow{2}{*}{ Return Rate (RR) } & $r$ & & 1 & $-0.384^{\star *}$ & $-0.174^{*}$ & $0.191^{*}$ \\
\hline & $p$ & & & 0.000 & 0.024 & 0.013 \\
\hline \multirow{2}{*}{ Academic Stressors (E-CEA) } & $r$ & & & 1 & $0.452^{* *}$ & -0.056 \\
\hline & $p$ & & & & 0.000 & 0.474 \\
\hline \multirow[b]{2}{*}{ Stress Response (R-CEA) } & $r$ & & & & 1 & $0.214^{* *}$ \\
\hline & $p$ & & & & & 0.005 \\
\hline \multirow{2}{*}{ Coping Strategies (A-CEA) } & $r$ & & & & & 1 \\
\hline & $p$ & & & & & \\
\hline
\end{tabular}

${ }^{* *}$ Correlation is significant at the 0.01 level (2-tailed). ${ }^{*}$ Correlation is significant at the 0.05 level (2-tailed). 


\subsection{Implications of Stress in the Academic Performance of Nursing Students}

To explore the relationship between the academic stressor variables being studied and their repercussions, with the objective of predicting academic performance on nursing students, a multiple linear regression analysis was carried out. The analysis revealed, as seen in Table 4, a coefficient of multiple correlation of 0.585 , of which $34.2 \%$ of the variability of the grade point average is explained by means of appraising academic stressors as predictive variables, as seen in the model. It was found out that academic stressors have an impact on the grade point average $(F=9.140, p<0.001)$, by means of correlation. The regression analysis (see Table 5) revealed significant relationship between academic stress among nursing students and their grade average. Specifically, the dimensions known as: Faculty methodological deficiencies, Public interventions, Low academic self-esteem, and Exams, were the academic stressors most significantly correlated $(p<0.05)$ to student academic performance based on academic grade point average.

With respect to the other variable, academic performance rate (Table 6), the analysis reflected a multiple correlation coefficient of 0.519 , with $27.0 \%$ of the variability of this rate explained by the academic stressors used as predictive variables established in the model. It was also found that academic stressors replicate or, are correlated in a statistically significant manner, along with the academic performance rate $(F=6.478, p<0.001)$.

The coefficients linked to this analysis (Table 7), showed significant relationship between nursing student academic stress and, the academic performance rate that showed the terms of either overcoming or approving enrolled credits. The dimensions Poor social relations within the academic context, Lack of control over own academic performance, and Exams, were the academic stressors significantly correlated $(p<0.05)$ with the nursing students' achievement based in the registered academic performance rate. As previously mentioned, this rate is based on the attempted (enrolled)-approved credit proportion.

Table 4. ANOVA of multiple linear regression analysis on the academic stressors subscale (E-CEA) and the academic grade average in a nursing students sample.

\begin{tabular}{cccccc}
\hline Model & $\begin{array}{c}\text { Sum of } \\
\text { Squares }\end{array}$ & $d f$ & Mean square & $F$ & Sig. \\
\hline Residual & 27.085 & 9 & 3.009 & 9.140 & 0.000 \\
Regression & & & & \\
& & & & & \\
Total & 79.025 & 158 & 0.329 & \\
$\mathrm{R}=0.585$ & & 167 & & \\
$\mathrm{R}^{2}=0.342$ & & & & \\
\hline
\end{tabular}


Table 5. Regression coefficients for the dimensions of the academic stressors subscale (E-CEA) and the academic grade average in the nursing students sample.

\begin{tabular}{|c|c|c|c|c|c|c|}
\hline & \multirow{2}{*}{ Model } & \multicolumn{2}{|c|}{$\begin{array}{l}\text { Unstandardized } \\
\text { coefficients }\end{array}$} & \multirow{2}{*}{$\begin{array}{c}\text { Standardized } \\
\text { coefficients }\end{array}$} & \multirow{2}{*}{$t$} & \multirow{2}{*}{ Sig. } \\
\hline & & B & $\begin{array}{l}\text { Standard } \\
\text { Error }\end{array}$ & & & \\
\hline & (Constant) & 3.906 & 0.175 & & 22.324 & 0.000 \\
\hline & Faculty methodological deficiencies & 0.171 & 0.076 & 0.224 & 2.264 & 0.025 \\
\hline & Student overload & -0.093 & 0.083 & -0.133 & -1.113 & 0.267 \\
\hline & Public Interventions & -0.118 & 0.052 & -0.180 & -2.280 & 0.024 \\
\hline & $\begin{array}{l}\text { Poor social relations within } \\
\text { academic context }\end{array}$ & -0.147 & 0.078 & -0.239 & -1.885 & 0.061 \\
\hline 1 & $\begin{array}{l}\text { Lack of control over own } \\
\text { academic performance }\end{array}$ & -0.191 & 0.103 & -0.255 & -1.860 & 0.065 \\
\hline & Lack of content values & -0.110 & 0.065 & -0.159 & -1.703 & 0.090 \\
\hline & Low Academic Self-esteem & 0.248 & 0.108 & 0.364 & 2.291 & 0.023 \\
\hline & Exams & -0.222 & 0.056 & -0.349 & -3.976 & 0.000 \\
\hline & $\begin{array}{l}\text { Impossibility of participation in } \\
\text { academic decisions }\end{array}$ & 0.024 & 0.084 & 0.037 & 0.292 & 0.770 \\
\hline
\end{tabular}

Table 6. ANOVA results of multiple linear regression of the dimensions of the E-CEA subscale and academic performance rate in the nursing students sample.

\begin{tabular}{|c|c|c|c|c|c|c|}
\hline & Model & Sum of Squares & $d f$ & Mean square & $F$ & Sig. \\
\hline & Residual Regression & $12,864.774$ & 9 & 1429.419 & 6.478 & 0.000 \\
\hline \multirow[t]{4}{*}{1} & & $34,864.224$ & 158 & 220.660 & & \\
\hline & Total & $47,728.998$ & 167 & & & \\
\hline & $\mathrm{R}=0.519$ & & & & & \\
\hline & $\mathrm{R}^{2}=0.270$ & & & & & \\
\hline
\end{tabular}

Table 7. Regression coefficients for the dimensions of the academic stressors subscale (E-CEA) and academic performance rate in the nursing students sample.

\begin{tabular}{|c|c|c|c|c|c|c|}
\hline & \multirow{2}{*}{ Model } & \multicolumn{2}{|c|}{$\begin{array}{l}\text { Unstandardized } \\
\text { coefficients }\end{array}$} & \multirow{2}{*}{$\begin{array}{c}\text { Standardized } \\
\text { coefficients } \\
\text { Beta }\end{array}$} & \multirow{2}{*}{$t$} & \multirow{2}{*}{ Sig. } \\
\hline & & $\mathrm{B}$ & $\begin{array}{l}\text { Standard } \\
\text { error }\end{array}$ & & & \\
\hline & (Constant) & 106.628 & 4.529 & & 23.541 & 0.000 \\
\hline & Faculty methodological deficiencies & 2.603 & 1.958 & 0.138 & 1.329 & 0.186 \\
\hline & Student overload & 0.159 & 2.159 & 0.009 & 0.074 & 0.941 \\
\hline & Public Interventions & -0.609 & 1.339 & -0.038 & -0.455 & 0.650 \\
\hline & $\begin{array}{l}\text { Poor social relations within the } \\
\text { academic context }\end{array}$ & -4.611 & 2.022 & -0.305 & -2.280 & 0.024 \\
\hline 1 & $\begin{array}{l}\text { Lack of control over own academic } \\
\text { performance }\end{array}$ & -6.231 & 2.658 & -0.339 & -2.345 & 0.020 \\
\hline & Lack in content values & -0.258 & 1.674 & -0.015 & -0.154 & 0.878 \\
\hline & Low Academic Self-esteem & 4.164 & 2.805 & 0.249 & 1.485 & 0.140 \\
\hline & Exams & -5.322 & 1.447 & -0.340 & -3.679 & 0.000 \\
\hline & $\begin{array}{l}\text { Impossibility of participation on } \\
\text { academic decisions }\end{array}$ & 1.545 & 2.167 & 0.095 & 0.713 & 0.477 \\
\hline
\end{tabular}




\section{Discussion}

The purpose of this research was to determine and analyze possible repercussions of academic stress in nursing students in a Puerto Rican private university and how it could affect academic performance in students. In this sense, one of the most important findings was an inverse and statistically significant relationship between the perception of academic stress upon considering the E-CEA stressors, and the academic performance in the nursing students' sample. The nine academic stressor dimensions correlated significantly with the academic grade point average and the academic performance rate. There is no doubt as to the relation that academic stress is related to the academic performance of nursing students. This is confirmed by Ponce Gomez et al. [18], at the mention of various studies in this field that find a similar relationship between academic performance and the stress situations generated by many academic factors, which will be mentioned further ahead. Nevertheless, not all the dimensions in the different research studies are the same or generate the most stress in the students [18]. Seron Cabezas [19], validated in his study the relationship between academic stress and the academic performance of nursing students. Nonetheless, according to MamaniConto [20], not all the studies related to academic stress and its relationship to academic performance coincide with the one conducted with Puerto Rican students. The MamaniConto [20] study, found the nursing students' academic performance to be fairly satisfactory (67.1\%), and, in comparison to the statistical analysis, the relationship between the variable and the student academic performance and its personal, academic and institutional factors was not significant.

Conversely, weak correlations were found between the Faculty methodological deficiencies dimension with Academic grade point average, and between the Lack of content values dimension with the academic performance rate. Gonzalez Cabanach et al. [21], pointed out in their study that it is the nursing students who significantly perceive a major lack of learning and studying content values. It is possible that the nursing plan of studies might not satisfy the nursing student initial expectations, or that the professional role models perceived might experience formative shortcomings. As a matter of analysis, the nursing faculty in Puerto Rico must reflect on the presented data, on the improvement of the nursing teaching methodology and, on the pertinence of the nursing course content.

The analysis of CEA global subscales and the variables of academic performance revealed that Academic Stressors (E-CEA) and Responses to Stress (R-CEA) were correlated inverse and significantly with performance variables. This suggests that the bigger the perception of the presence of academic stressors and responses to stress with adverse symptoms contrary to student physical, behavioral and cognitive wellbeing, the lesser the student's academic performance. This finding coincides with a study carried out by Mendoza et al. [8], which found that students who possess a negative perception about their academic 
performance when immersed in a stressful situation, they interpret it as academic stress and tend to inversely relate this perception to their academic performance. The more the academic stress and the perception of inability to overcome it, the lesser the student academic achievement [22] [23] [24] [25].

On the other hand, the Coping Strategies subscale (A-CEA) kept a statistically significant correlation to the academic performance rate. Significant correlations were observed between the academic performance rate and the three dimensions of A-CEA: Search for support, Planning, and Positive reassessment. Also, and among the results, it is the Search for support dimension, the one with the highest coefficient, although a weak one, with the academic performance rate. According to this, similar studies have demonstrated that nursing students who used cognitive-behavioral and relaxation techniques showed an increase on academic performance [26]. On analyzing Puerto Rican nursing student successful strategies on coping with academic stress, the successful ones were those who assessed the strengths found in the cognitive-conceptual part of the university life foundation skills. This search for academic support strategies, implies a level of maturity actively translated into the use of time, in the search of academic counseling, on finding different approaches to address academic difficulties and, above all, reassessing each situation that comes his or her way with a positive, optimistic demeanor. Another study concludes that there seems to exist a significant, negative reaction between the effectiveness and the degree of what the nursing student perceives, the degree in which the student assesses different academic situations in terms of personal threat to his or her academic wellbeing, and the index of informed physical and psychological degree of upset [21]. Therefore, those nursing students that seek positive academic support strategies when undergoing academic stress have better success possibilities that those who do not.

Finally, the general aim of this study was to determine and to analyze the implications of academic stress in the performance of nursing students at a Private University in Puerto Rico. To accomplish this, a multiple linear regression analysis was used to explore the relationship between the variables under study regarding academic stressors and their repercussions to predict the academic performance in nursing students. Among the findings, it was found that academic stressors are correlated with academic performance. The dimensions known as Faculty methodological deficiencies, Public interventions, Low academic self-esteem and Exams were the academic stressors most significantly correlated to the academic performance of nursing students based on the academic grade point average. Studies measuring this situation coincide with the findings on the nursing students in Puerto Rico, which specifically indicate that the dimensions Faculty methodological deficiencies and Exams are related to the academic performance of nursing students [21]-[27]. Similarly, it has been found that the dimensions concerning Public interventions and Low academic self-esteem affect the academic performance and grade point average of nursing students, when con- 
fronted with high levels of stress [28]. Other studies, in contrast with the one carried out in Puerto Rico, found that other different set of variables related with academic performance, such as the one that states that nursing students who adopt a daily study habit, turn out the best academic grade point averages [29], and the close relationship between psychological wellbeing and academic performance, which supposes a better academic grade point average [30].

With respect to the variable academic performance, the multiple regression analysis showed that the academic stressors are correlated in a statistically significant manner to the academic performance rate. Significant relationship between academic stress in students and the academic performance rate is evident. Academic stress on nursing students and the academic performance rate, specially, showed that the difficulty to overcome or approve the attempted (enrolled) credits are related to academic stressors. The dimensions which refer to Poor social relations within the academic context, Lack of control over own academic performance, and Exams were the academic stressors most significantly related to the nursing student academic performance based on the proportion of attempted-approved credits. This finding coincides with studies which point to the fact that most students who control their academic stress and use managing strategies to face these situations, improve their academic performance [8]. There is a relationship between the management of the academic stress levels and the academic performance of nursing students. Also, it has been demonstrated that academic demands and academic stress considerably diminish student performance, thus producing low educational achievement, depressed or highly stressed students due to personal issues, a matter that also affects student academic performance [17]-[24]. Academic stress also affects attendance; since lack of attendance due to student maladaptation, causes poor academic performance that may result in academic failure on the part of the student, or even causing the student to drop out of the university [24]. Stress is known to be an adaptive phenomenon on human beings that, contributes, in good measure, to its survival, to adequate performance in their activities, and to the enrichment of life in general [24].

Despite the findings encountered in the Puerto Rican study, they are considered not sufficient by themselves to establish trend predictions applicable to other nursing students. Regardless to the subject of academic stress being a common health issue among nursing students at the university level, it has not been sufficiently studied [8]. Notwithstanding of the finding's analysis, conclusions and recommendations must be developed and implemented to further help students on coping with this academic disorder, and to motivate researchers to carry out further research on this topic.

\section{Conclusion}

It was found that academic stressors are correlated to the academic grade point average. It was also found that the academic stressors that affect nursing stu- 
dents the most at the university under study are caused by: Faculty methodological deficiencies, Public Interventions, Low Academic Self Esteem, and Exams. These, in turn, also significantly are related to the academic performance of nursing students based on their academic grade averages. Considering the other academic variable, it was found that academic stressors are significantly correlated within the academic performance rate. It was also noted that significant relationship exists between academic stress among nursing students, and the academic performance rate. Findings showed, among students under study, that the capability of succeeding or approving the academic courses was related to academic stressors. Among them, emphasize must be paid to Bad social relations within the academic context, Lack of control over their own academic achievement and Exams. These being the academic stressors directly and significantly related to academic achievement of nursing students based on the academic performance rate, evidenced by the relationship among attempted-approved credits.

\section{Limitations}

1) Despite being a random and representative sample, as it is specific for said program, it is difficult to generalize the results to the population of university students in Puerto Rico.

2) Due to the cross-sectional nature of this study, it limits the possibility of determining to what extent academic stress can become a burning syndrome during the years of study, and if indeed, what are the life experiences of nursing students during stress processes academics. The first could be achieved by means of a longitudinal study, and the second by means of a qualitative study.

\section{Conflicts of Interest}

The authors declare no conflicts of interest regarding the publication of this paper.

\section{References}

[1] Alves Apóstolo, J.L., Alves Rodrigues, M. and Pineda Olvera, J. (2007) Assessment of the Nursing Students' Emotional States. Index de Enfermería, 16, 26-29. https://doi.org/10.4321/S1132-12962007000100006

[2] Firth-Cozens, J. (2001) Medical Student Stress. Medical Education, 35, 6-7.

[3] Herrera, L.M. and Rivera, M.S. (2011) Prevalence of Psychological Distress in Nursing Students Associated with Sociodemographic, Academic and Family Factors. Ciencia y Enfermería, 17, 55-64. https://doi.org/10.4067/S0717-95532011000200007

[4] Lo, R. (2002) A Longitudinal Study of Perceived Level of Stress, Coping and Self-esteem of Undergraduate Nursing Students: An Australian Case Study. Journal of Advance Nursing, 39, 119-126. https://doi.org/10.1046/j.1365-2648.2000.02251.x

[5] Radcliffe, C. and Lester, H. (2003) Perceived Stress during Undergraduate Medical Training: A Qualitative Study. Medical Education, 37, 32-38. 
https://doi.org/10.1046/j.1365-2923.2003.01405.x

[6] Vengoechea, J., Ruíz, A. and Moreno, S. (2006) Stress and Misconduct in Students of a Medical School in Bogotá. Revista Colombiana de Psiquiatría, 35, 341-352.

[7] Casuso Holgado, M.J. (2011) Study of Stress, Engagement and Academic Performance in College Students of the Health Sciences. Tesis Doctoral, Universidad de Málaga Facultad de Enfermería, Fisioterapia, Podología y Terapia Ocupacional. https://core.ac.uk/download/pdf/62896672.pdf

[8] Mendoza, L., Cabrera Ortega, E., González Quevedo, D., Martínez Martínez, R., Pérez Aguilar, E. and Saucedo Hernández, R. (2010) Factorsthat Cause Stress in University Students. ENE, Revista de Enfermería, 4, 36-46.

[9] Gomathi, K.G., Ahmed, S. and Sreedharan, J. (2012) Psychological Health of First-Year Health Professional Students in a Medical University in the United Arab Emirates. Sultan Qaboos University Medical Journal, 12, 206-213.

[10] Puerto Rico Council on Higher Education (2010) Consejo de Educación Superior de Puerto Rico. CESPR History and Rules. http://www.cespr.org/

[11] Universidad del Turabo (2014) Informe de Logros Programa de Enfermería-UT (2014) UT-Nursing Program Achievement Report: Bachelor Program in Nursing Sciences Annual Statistics. Universidad del Turabo, Gurabo.

[12] Edwards, D., Burnard, P., Bennett, K. and Hebden, U. (2010) A Longitudinal Study of Stress and Self-Esteem in Student Nurses. Nurse Education Today, 1, 78-84. https://doi.org/10.1016/j.nedt.2009.06.008

[13] Illesca, M., Cabezas, M., Romo, T. and Díaz, P. (2012) Nursing Students' Opinion about the Objective Structured Clinical Examination. Ciencia y Enfermería, 18, 99-109. https://doi.org/10.4067/S0717-95532012000100010

[14] Oliveti, S.A. (2010) Academic Stress in Students Enrolled in First Year of the University Context. Tesis para obtener Licenciatura en Psicología, Facultad de Psicología y Relaciones Humanas. Universidad Abierta Interamericana.

https://www.academia.edu/34641128/Estres_academico_primer_a\%C3\%B1o_unive $\underline{\text { rsitario }}$

[15] Vallejo-Agudelo, E.O., Martínez-Sánchez, L.M. and Agudelo-Vélez, C.A. (2013) Stress: Generic Determinant of Academical Performance. Revista de Educación y Desarrollo, 26, 89-93.

[16] Yamashita, K., Saito, M. and Takao, T. (2012) Stress and Coping Styles in Japanese Nursing Students. International Journal of Nursing Practice, 18, 489-496. https://doi.org/10.1111/j.1440-172X.2012.02056.x

[17] Cabanach, R.G., Valle, A., Rodríguez, S. and Piñeiro, I. (2008) Stress Response in University Contexts: Constructionof a Measurement Scale. V Congreso Internacional de Psicología y Educación: Los retos de futuro, Oviedo, 23-25.

[18] Ponce Gómez, A.M., Jiménez Salgado, J.C. and López Pérez, O. (2010) Relationship between Academic Stress and Performance in Those Students Enrolled to the Program of Tutorials of the Psychology College.

http://www.tutoria.unam.mx/SextoEncuentroNacional/Memoria/files/JISJ93_PE4R 3_500.pdf

[19] Serón Cabezas, N. (2006) Relation that Exists between Stress Factors and Academic Performance of the Nursing Students of the U.N.M.S.M. Tesis Doctoral, Facultad de Medicina Humana, E.A.P de Enfermería de la Universidad Nacional Mayor de San Marcos. http://cybertesis.unmsm.edu. pe/handle/20.500.12672/1009

[20] Mamani Conto, G. (2000) Relationship of Personal, Educational and Institutional 
Factors with the Academic Performance of Nursing Students of the U.N.M.S.M. Tesis para optar grado de Magíster en Enfermería, Lima-Perú. https://cybertesis.unmsm.edu.pe/handle/20.500.12672/ 6295

[21] González Cabanach, R., Fernández Cervantes, R., González Doniz, L. and Freire Rodríguez, C. (2010) Academic Stressors Perceived by University Students of Health Sciences. Fisioterapia, 32, 151-158. https://doi.org/10.1016/j.ft.2010.01.005

[22] Caldera Montes, J.F., Pulido Castro, B.E. and Martínez González, M.J. (2007) Levels of Stress and Academic Performance in Psychology Students of the University of Los Altos. Revista de Educación y Desarrollo.

http://www.cucs.udg.mx/revistas/edu_desarrollo/anteriores/7/007_Caldera.pdf

[23] Cárdenas, J.C. (2012) The Academic Stress, Causes and Consequences.

http://cancelacionesicesi.blogspot.mx/2012/11/ensayo-final-el-estres-academico-cau sas.html

[24] Morrison, R. and O'Connor, R.C. (2005) Predicting Psychological Distress in College Students: The Role of Rumination and Stress. Journal of Clinical Psychology, 61, 447-460. https://doi.org/10.1002/jclp.20021

[25] Valenzuela Pablos, L.M. and Fraijo Sing, B.S. (2011) Integration and Stress in College Students. Ponencia XI Congreso Nacional de Investigación Educativa Universidad Pedagógica Nacional. http://www.comie.org.mx/congreso/memoriaelectronica/v11/docs/area_16/2151.pdf

[26] Maldonado, M.D., Hidalgo, M.J. and Otero, M.D. (2000) Program of CognitiveBehavioral Intervention and Relaxation Techniques as a Method to Prevent Anxiety and Stress in University Students of Nursing and Improve Academic Performance. Cuadernos de Medicina Psicosomática, 53, 43-57.

[27] González Cabanach, R., Fernández Cervantes, R. And González Doniz, L. (2014) Academic Stress in Students of Health Sciences. Fisioterapia: Revista de Salud, Discapacidad y Terapéutica Física, 36, 101-102. https://doi.org/10.1016/j.ft.2014.03.002

[28] Barraza Macías, A. (2007) Estrés Academic Stress: A State of the Art. http://www.psicologiacientifica.com/bv/psicología-232-1-estrés-acade

[29] Burgos Monago, E. and Marín Ferrer, J.M. (2010) Academic Stress in College Students.

http://www.scribd.com/doc/28105721/Estres-academico-en-los-estudiantes-univers itarios

[30] Arribas Marín, J. (2011) Toward a Causal Model of the Dimensions of Academic Stress in Nursing Students. Revista de Educación, 360, 533-556. 